\title{
Joint work in paediatrics: a child psychiatry perspective
}

\author{
J C STURGE
}

Department of Child Psychiatry, Northwick Park Hospital, Harrow

Child Psychiatry (as one of the 'Cinderella' specialities) has had to look carefully at its interface with other disciplines and at the management of the referral stage of cases. Because so much of our work is in liaison with others, failure to clarify the expectation of the referral, the degree of collaboration needed and who is taking responsibility for what, results in dissatisfactions and misunderstandings for the referrer.

This paper is written in the hope that some of this 'thinking through' that we have undertaken might be helpful to paediatricians making tertiary referrals. First, practices in child psychiatry are considered and then possible implications in paediatrics considered.

\section{Practices in child psychiatry}

Several types of response can be offered to referrals to child psychiatric teams. These are:

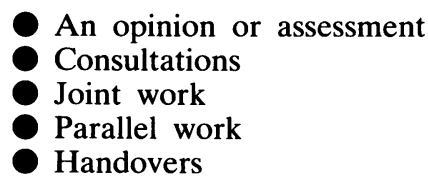

\section{AN OPINION}

This is self evident. A referrer asks for an opinion, for example whether a 9 year old boy who keeps hearing his grandfather's voice talking to him is psychotic. Total responsibility remains with the referrer.

\section{A CONSUltation}

A social worker brings a family to see us. Together with the family the problem is presented, for example those consulting want our advice on how to manage an adolescent's violence. They have worked on the problem and feel stuck. Taking the views of both the social worker and the family into account we make an intervention-jargon for a carefully worded statement designed to change the en- trenched situation. Those consulting us can reject or accept our view.

\section{JOINT WORK}

An education social worker (known as an education welfare officer in some areas) refers a family asking to work jointly with us in getting a school refuser back into school. A social worker refers a family for joint work where there has been intrafamilial sexual abuse. The aim is to work with the family and effect sufficient change for the perpetrator to be reintegrated into the family. Responsibility for the work effecting change is joint: the statutory responsibility in the second example for protecting the child remains with social services.

\section{PARALLEL WORK}

A social worker refers a 4 year old child for help with his encopresis. She is meanwhile working with the family on parenting skills. The two agencies take responsibility for different areas of work. They are not independent of each other, however, and this is the least successful model of working.

\section{HANDOVER}

Again self explanatory. An educational psychologist refers a family saying the family is complaining of problems that are entirely home and not school related. The referrer plays no further role.

In all these examples responsibility for primary care of course remains with the general practitioner who is kept informed.

\section{Child psychiatric joint work and liaison work with paediatrics}

Using the same models, the following are established at the point of referral (see table for examples):

- Expectation of the referral

- Degree of collaboration needed

Areas of responsibility 


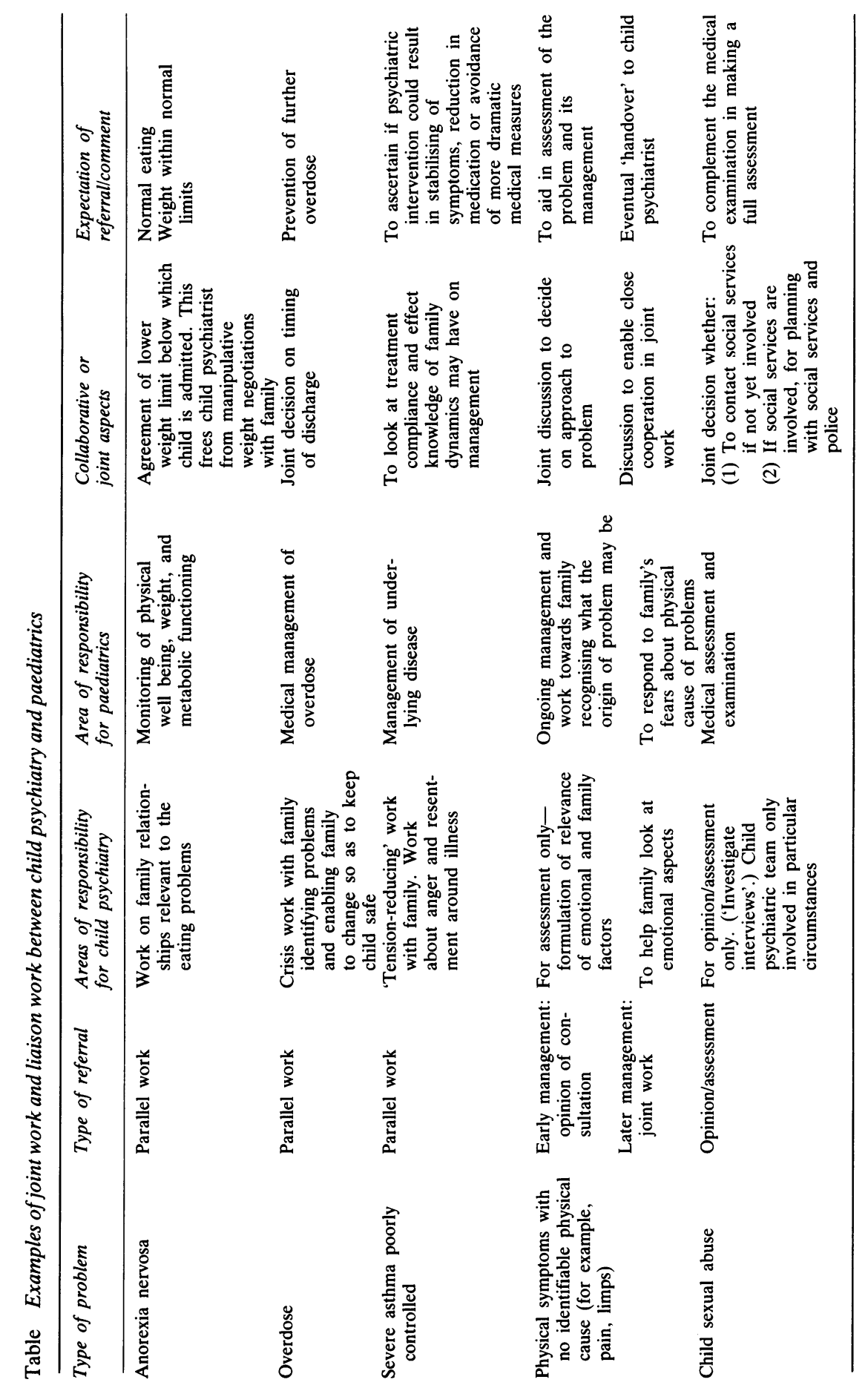

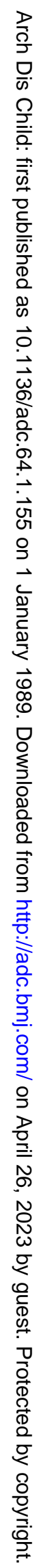




\section{GENERAL COMMENTS}

While much of the work is in parallel, the joint collaborative role is of great importance to the successful management of all these problems.

\section{HANDOVERS}

The only clearcut case for handovers is when the paediatricians see what turns out to be an inappropriate referral-for example, a general practitioner refers what purports to be a vomitting problem. On assessment this is clearly a case of bulaemia, that is, self induced vomiting.

More commonly paediatricians seek to hand over cases where they consider the origin of a physical symptom to be psychogenic. Rarely, however, has the family reached this point early in the management of the problem and handover to the child psychiatrists can be counter productive when the family attends 'under duress', still convinced the doctors have simply not investigated fully enough. When families are beginning to look at the possibility of emotional factors joint work can be useful so that the 'expert' on the physical aspects is present to help deal with family's need to somatise problems.

Additionally, we all, of course, have anecdotes of referrals of this type, where later a serious physical condition is identified.

\section{CONSULTATIONS}

Paediatricians rarely use this direct face to face form of seeking an opinion in conjunction with the family. It can often reduce the family's resistance to being 'delivered' to the child psychiatric team and expelled from the paediatric arena. A disadvantage is that it is time consuming-the child psychiatrist needs to make an assessment of the family in order to comment.

\section{Some observations on tertiary referrals in paediatrics: 'shared care'}

Difficult situations seem too often to arise with this type of referral. The commonest example of this is where the tertiary centre takes over the 'expert' management of the problem while the secondary centre (referring paediatrician) is expected to provide emergency cover or ongoing day to day care. This can result in:

(1) Problems in management of the acute situations because the parents lack faith in the local service and undermine necessary changes in treatment.

(2) Liaison with local services-for example, schools, physiotherapists, etc-not being as coordinated as it should be.
The reasons for the problems are usually:

(1) Failure to clarify at the point of referral the model of shared care being sought.

(2) Failure to clarify discrete areas of responsibility and, in particular, failure to make clear to the family who is responsible for what.

(3) Geographical distance between the two centres making close collaboration difficult.

To avoid this problem referrals to tertiary centres should be understood by all those involved (referrer, family and tertiary centre) and be for one of the following reasons:

(1) For opinion and advice only (responsibility remains with referring paediatrician).

(2) For takeover of care for an agreed period with responsibility passing back to the referrer at the end of this time.

(3) For a long term handover of care when tertiary centre takes over responsibility, liaising with the general practitioner.

(4) For consultations.

Joint clinics are becoming more widely available and offer an excellent opportunity for close collaboration and clear definition of roles and responsibilities.

In my view this could be improved still further by using a model closer to that described in child psychiatry where consultations are offered. It would be clearer to the family that the referring paediatrician and they themselves were seeking the consultation if the referring paediatrician were to fetch them in and then sit with the family (and not with the 'specialist') and jointly consult. At the end there should be an opportunity for the referring paediatrician and family to discuss, in the absence of the 'specialist', their reaction to the opinion given and whether or not they (family and referring paediatrician) want to act on the advice given. This makes very clear the nature of the referral-that responsibility remains with the referring paediatrician-and can enhance relationships by fully involving the family.

\section{Shared care: a misnomer}

The term shared or joint care when the term used is in relation to a paediatrician referring to an expert at another centre is usually a misnomer: it is not the overall care that is shared but other aspects of management. Central responsibility cannot be shared where those trying to share it do not work alongside and are not in frequent contact within the same establishment. The situation is analogous to 
158 Sturge

divorced parents. Joint care and control can only work where parents are living together. Judges and the courts are now clear that joint care and control are not in the best interests of the child but that for continuity and sense of security, care and control should be with one parent only and with the parent most frequently in contact with the child. Joint custody is sometimes granted (though less and less so), and extending the analogy, this would mean that the local paediatrician (parent with care and control) would consult with the 'specialist' (parent with access only) over major decisions (joint custody issues).

Correspondence to Dr JC Sturge, Department of Child Psychiatry, Northwick Park Hospital, Watford Road, Harrow, Middlesex HA1 3UJ. 